\title{
Diversity in an Information Polity
}

This edition provides a diverse set of papers, each of them speaking to different aspects of the 'information polity' whilst, simultaneously and as a collection, representing significant 'outlier' topics each of which suggest that more research should be done and more studies published in these areas. This is especially true in the area of freedom of information. This, one might imagine, should be a mainstream area for studies of the information polity yet, surprisingly, is relatively neglected. Here I am grateful to Guest Editor, Dr Eleanor Burt of St Andrews University, Scotland, for drawing together a stimulating set of papers for which she provides her own introduction below. I am especially pleased that her small collection of papers on FOI includes one from a prominent practitioner, the Scottish Information Commissioner, and I am equally pleased that the Commissioner raises issues surrounding a new form of FOI: that pursued by Wikileaks.

The topicality of Wikileaks is matched too by the paper of Taewoo Nam when he discusses the use and influence of social networking in the US Presidential election of 2008. Here again is a theme that demands more attention and I am certain that it will receive such attention as we come to understand more and more of the significance of social networks, including Facebook, Twitter and YouTube, for the conduct of democratic discourse in the modern polity. In one important sentence Taewoo Nam crystallises the gathering significance of social networking sites [SNS]. He says "Despite the conventional reality that the better educated and the more affluent have more opportunities for political information, communication and mobilization - "politics as usual" - political activity on SNS reveals more equalized participatory patterns". However, this author goes on to show that whilst this first assertion is true much inequality continues to exist in participatory democratic patterns, much of which follows historic patterns of inequality in the US polity. Taewoo Nam shows both scepticism and optimism in more or less equal measure therefore in terms of the viewing the Internet as a 'progressive' democratising environment.

An entirely new topic for this journal is that of minority language availability on the Internet for political communication. Daniel Cunliffe examines the availability of the Welsh language on political sites at the UK's last general election in 2010. Just as Taewoo Nam investigates the 'equalising' influence of the Internet so too does Cunliffe, though here that equalisation is contingent on the inclusion of a specific language. Surprisingly Cunliffe finds that the number of political parties offering bi-lingual [Welsh/English] websites declined between 2005 and 2010 to three rather than four, as earlier. One party that actually has Welsh members of parliament does not offer any Welsh language content whatsoever [Conservative]. Cunliffe cites evidence that Welsh speakers are more like to vote for Plaid Cymru, the Welsh Nationalist Party, than any other Party and yet even here Welsh language provision has significant limitations. Cunliffe concludes: "Overall, the Welsh language does not appear to have been a priority in terms of online political communication for most of the parties campaigning in Wales during the 2010 General Election. While the actual effect of this on the electorate's opinions and voting behaviour remains unknown, it may cause concern for those interested in the long-term survival of the Welsh language", a conclusion that reaches out to cultural heritage as much as to political communication.

In our final paper, Marijke Teerling and Willem Pieterson examine the prospect of shifting citizen preference for traditional methods of interaction with government [face to face or 'front desk' as they 
call it] to multi channel strategies that bring citizens more into on-line relationships thereby realising cost efficiencies as well as enhanced satisfaction levels. These authors thereby address a matter of fundamental importance to governments: how can e-government, meaning service delivery on-line, be advanced so that it is adopted by large numbers of citizens and embedded in their behaviour. The authors present their findings from an impressively large and well-designed research project in a lucid and thoughtful way showing different preferences for different channels for different groups of citizens. More than that, they reveal those measures that, if taken by government, would increase take-up of the on-line option. Teerling and Pieterson say in their conclusions that: "Both practitioners in the field of service channels as well as multichannel management theorists should take into account the results of this study when building or enhancing their strategies, models or theories". I entirely agree with this judgment. I hope readers of Information Polity who are in these categories will read this excellent paper and derive benefit from it. And, of course, I trsut that all of our readers will gain from reading it as well as all the other papers that appear in what I believe to be a stimulating edition.

JA Taylor. May, 2011. 